\title{
Preparation of a Thermally Modified Diatomite and a Removal Mechanism for 1-Naphthol from Solution
}

\author{
Xiuzhen Yang ${ }^{1,2}$, Yuezhou Zhang ${ }^{3, *}$, Liping Wang ${ }^{4, *}$, Lili Cao ${ }^{4}$, Kelin $\mathrm{Li}^{4}$ \\ and Andrew Hursthouse 1,5 \\ 1 College of Civil Engineering, Hunan University of Science and Technology, Xiangtan 411201, China; \\ yxzhy1102@126.com (X.Y.); andrew.hursthouse@uws.ac.uk (A.H.) \\ 2 Hunan Provincial Key Laboratory of Shale Gas Resource Utilization, Xiangtan 411202, China \\ 3 Pharmaceutical Sciences Laboratory, Faculty of Sciences and Engineering, Åbo Akademi University, \\ FI-20520 Turku, Finland \\ 4 School of Environmental and Safety Engineering, Changzhou University, Changzhou 213164, China; \\ caoli123li@126.com (L.C.); like123lin@126.com (K.L.) \\ 5 School of Science \& Sport, University of the West of Scotland, Paisley PA1 2BE, UK \\ * Correspondence: zyuezhou@126.com (Y.Z.); wlp@cczu.edu.cn (L.W.); Tel.: +358-449891210 (Y.Z.); \\ +86-519-86330087 (L.W.)
}

Received: 28 June 2017; Accepted: 28 August 2017; Published: 30 August 2017

\begin{abstract}
The adsorption of 1-naphthol (NAP) in aqueous solution was investigated using unmodified and modified diatomite at different temperature, $\mathrm{pH}$, adsorbent mass and contact time. The adsorption capacity of the modified diatomite significantly improved (about 2 times at $298 \mathrm{~K}$ ) compared to the unmodified diatomite. The adsorption showed a good fit with the Langmuir model. The further data analysis demonstrated that the adsorption of 1-NAP on both materials could be best described by the $p s e u d o$ second-order kinetic model. The thermodynamic parameters, including Gibbs' free energy $(\Delta G)$, enthalpy $(\Delta H)$ and entropy changes $(\Delta S)$ were determined. It was observed that the $\Delta H$ values (less than $40 \mathrm{~kJ} / \mathrm{mol}$ ) was positive, which indicated that the adsorption process is endothermic, physical adsorption. The $\Delta G$ values were negative, indicating that the adsorption of 1-NAP onto raw and modified adsorbent was spontaneous.
\end{abstract}

Keywords: 1-naphthol; diatomite; kinetic; adsorption; thermodynamics

\section{Introduction}

Contamination of water and soil by synthetic aromatic compounds is one of the most severe environmental problems that cause serious harm to human beings and aquatic ecosystems [1]. In particular 1-naphthol (1-NAP), widely used in the manufacture of industrial compounds, is one of top priority contaminants among naphthalene analogues and also the main carcinogenic pollutants discharged from pharmaceutical, dyestuff, photographic, and agrochemical industries, particularly in developing countries [2]. It is of particular concern due to its severe toxicity and adverse effects on the environments. However, the removal of 1-NAP cannot be readily accomplished in the natural environment or in biological water treatment plants. Therefore, the efficient elimination of 1-NAP from the environment is of interest.

Up to now, many methods have been used to remove naphthalene analogs, such as biological degradation [3], ozonation [4], photocatalytic degradation [5], and adsorption [6], etc. Their application is challenged by poor treatment efficiency, difficulty in generating microbial consortia, expensive analysis, and the generation of secondary pollutants $[7,8]$. Among them, adsorption has been found to be potentially an effective and attractive process for the wastewater treatment because of low operational cost and high efficiency in the preconcentration process. 
A range of adsorbents have been studied for 1-NAP removal, including sulfonated graphene nanosheets [1], hydrophilic hyper-cross-linked polymer resin [2], and coal-derived activated carbon [9]. Due to the availability and excellent physicochemical characteristics of diatomite $[10,11]$, in acting as potential sorbent for pollutant removal. To the best of our knowledge, there is little information on the adsorption of 1-NAP using diatomite.

Diatomite is well known low-cost and commercially available absorbent for the adsorption of different heavy metal ions and organic compounds from water and wastewaters [12].

This work investigated the feasibility of 1-NAP adsorption by thermal modification of raw diatomite. Surface properties of diatomite before and after modification were characterized by means of scanning electron micrograph (SEM) and Fourier-transform infrared (FT-IR) spectra. Several key experimental parameters were investigated, including water temperature, $\mathrm{pH}$, adsorbent mass, as well as contact time. The experimental data were analyzed through Langmuir, Freundlich and D-R adsorption models. The kinetic adsorption results have been analyzed using pseudo-first-order, pseudo-second-order reactions and intraparticle diffusion model. The adsorption mechanism was also carried out according to thermodynamics and kinetics principles.

\section{Experiments}

\subsection{Materials}

Sodium hydroxide $(\mathrm{NaOH})$, sulfanilic acid, sodium nitrite $\left(\mathrm{NaNO}_{2}\right)$, 1-NAP, ethanol, sulfuric acid were obtained from Sinopharm Chemical Reagent Co., Ltd. (Shanghai, China). All chemicals in this work were analytically pure and used without further purification.

The raw diatomite used in this study was purchased from Venture Chemical Co., Ltd. (Osaka, Japan). Before use, the diatomite sample was powdered by pounding in a porcelain mortar and washed several times by distilled water and then dried overnight in an oven at $100{ }^{\circ} \mathrm{C}$. To make thermally modified diatomite, a natural diatomite sample was heated and held at $450{ }^{\circ} \mathrm{C}$ for $2 \mathrm{~h}$, and then it was cooled in desiccators. It was put into polyethylene bags and stored to use in the future.

\subsection{Characterization}

The Scanning electron microscope (SEM) images of natural diatomite and thermal modified diatomite were observed using JSM-7001F (JEOL Ltd., Tokyo, Japan). Fourier-transform infrared (FT-IR) spectra were recorded on a Nicolet NEXUS-470 FT-IR apparatus (GMI, Minneapolis, MN, USA) from 400 to $4000 \mathrm{~cm}^{-1}$, in order to investigate the surface characteristic of modified diatomite and adsorbed diatomite. The 1-NAP concentration was determined by a UV-visible spectrophotometer (UV-2450, Shimadzu, Kyoto, Japan). The solution $\mathrm{pH}$ was controlled by a precision $\mathrm{pH} / \mathrm{mV}$ meter (PHB-9901, Shanghai, China). Batch adsorption experiments were performed using a constant temperature oscillator (THZ-C, Huamei Biochemical Instrument Factory, Taicang, China). All chemicals and materials were weighed by electronic analytical balance (MS205DU, METTLER TOLEDO, Shanghai, China). The supernatant was separated from the mixed solution using the centrifuge (TDL-5-A, Shanghai Anting Scientific Instrument Factory, Shanghai, China) in the adsorption experiments.

\subsection{Adsorption Experiments}

The adsorption capacity of raw diatomite and modified diatomite to 1-NAP was investigated as a function of contact time, $\mathrm{pH}$, temperature and the dosage of diatomite. In this study, the adsorption experiments were performed using a batch technique. The adsorption characteristics were examined by mixing $0.1,0.2,0.3,0.4,0.5$ and $0.6 \mathrm{~g}$ of natural diatomite and modified sample in $100 \mathrm{~mL}$ simulated water samples with an aninitial concentration of 1-NAP $10 \mathrm{mg} / \mathrm{L}$. The $\mathrm{pH}$ of the solution was adjusted using $0.1 \mathrm{~mol} / \mathrm{L} \mathrm{HCl}$ or $\mathrm{NaOH}$ without adding any buffer. The resulting mixtures were shaken in a constant thermostatic oscillator at $150 \mathrm{rpm}$, Experiments were undertaken at different temperatures 
$\left(15,25,35\right.$ and $\left.45{ }^{\circ} \mathrm{C}\right)$ for one hour. The supernatant were centrifuged at $1000 \mathrm{rpm}$ for $10 \mathrm{~min}$ and then collected and analyzed by UV-visible spectrophotometer to determine the concentration of 1-NAP. The amount of 1-NAP adsorbed with was determined by mass balance equation given UV absorption values.

\subsection{Measurement of 1-NAP}

In this study, the concentration of 1-NAP was determined via the following method. $3 \mathrm{~mL} 2 \mathrm{~g} / \mathrm{L}$ sodium nitrite and $2 \mathrm{~mL} 4 \mathrm{~g} / \mathrm{L}$ sulfanilic acid was mixed in six glass beakers at temperatures less than $5{ }^{\circ} \mathrm{C}$, respectively. Afterwards, $2 \mathrm{~mL} 6 \mathrm{~mol} / \mathrm{L}$ sodium hydroxide was added to the mixture solution and then different concentrations of 1-NAP were added (0.896, 1.344, 1.792, 2.240, 2.688, 3.136, $3.584 \mathrm{mg} / \mathrm{L})$ at experimental temperature $>20^{\circ} \mathrm{C}$, to create calibration standards. After $25 \mathrm{~min}$, the colored solutions at different concentrations were scanned by UV-visible spectrophotometer at $230 \mathrm{~nm}$ (UV-2401 UV/vis spectrophotometer, Shimadzu Scientific Intruments, Kyoto, Japan); the detection limit is $0.03 \mathrm{mg} / \mathrm{L}$. Each experiment was repeated at least three times to get effective data.

\subsection{Adsorption Equilibrium Isotherm}

Various models of adsorption equilibrium have been reported to describe the adsorption process $[8,13]$. Most of models are condition specific. For example, Langmuir, Freundlich and D-R isotherm models were applied to describe the isotherm issue, which were used to characterize the surface properties and affinity of the adsorbent.

A basic assumption of the Langmuir theory is monolayer sorption onto surface with a finite number of identical sorption sites. The model can be written in a linear form [14,15]:

$$
\frac{1}{q_{e}}=\frac{1}{K_{L} Q_{m}} \times \frac{1}{C_{e}}+\frac{1}{Q_{m}}
$$

where $q_{e}$ is the concentration of 1-NAP on sorbent at equilibrium $(\mathrm{mg} / \mathrm{g}), C_{e}$ is the concentration of 1-NAP in the solution at equilibrium $(\mathrm{mg} / \mathrm{L}), K_{L}$ is the Langmuir adsorption constant $(\mathrm{L} / \mathrm{mg})$ and $Q_{m}$ $(\mathrm{mg} / \mathrm{g})$ is the theoretical maximum adsorption capacity $(\mathrm{mg} / \mathrm{g})$.

The Freundlich isotherm assumes a heterogeneous adsorption surface and active sites with different energy [16]. Its equation is given as follows:

$$
\log q_{e}=\log K+\frac{1}{n} \log C_{e}
$$

where the constant $K(\mathrm{mg} / \mathrm{g})$ is an approximate indicator of adsorption capacity and $n$ is the empirical parameter related to the intensity of adsorption.

The equilibrium data were also applied to the D-R isotherm model [17] to determine the nature of adsorption process:

$$
\ln q_{e}=\ln V_{m}-K_{F} \varepsilon^{2}
$$

where $V_{m}$ is D-R adsorption capacity ( $\mathrm{mg} / \mathrm{g}$ ), the constant $K_{F}$ related to adsorption energy $\left(\mathrm{mol}^{2} / \mathrm{kJ}^{2}\right)$, $\varepsilon$ is Polanyi potential $(\mathrm{kJ} / \mathrm{mol})$, which is calculated as following:

$$
\varepsilon=R T \ln \left(1+\frac{1}{C e}\right)
$$

where $R$ is gas constant $(\mathrm{kJ} / \mathrm{K} \mathrm{mol})$ and $T$ is temperature $(K)$.

\subsection{Kinetic Equation}

To explore reaction mechanism and pathways between the adsorbate and the adsorbent, the kinetic batch data were analyzed using pseudo first-order model, pseudo second-order model and intraparticle 
diffusion model $[18,19]$ respectively. The correlation coefficient $\left(R^{2}\right)$ was considered as a measurement of the agreement between the experimental data and the three proposed models.

The $p s e u d o$-first kinetic order equation can be written as [20]:

$$
\ln \left(q_{e}-q_{t}\right)=\ln q_{e}-k_{1} t
$$

where $q_{e}$ and $q_{t}(\mathrm{mg} / \mathrm{g})$ are the adsorption capacity at equilibrium and at time $t$, respectively. $k_{1}\left(\mathrm{~min}^{-1}\right)$ is the rate constant of the pseudo-first order model.

The pseudo second-order adsorption equation is described as [21]:

$$
\frac{t}{q_{t}}=\frac{1}{k_{2} q_{e}^{2}}+\frac{t}{q_{e}}
$$

where $k_{2}$ is the second-order rate constant $(\mathrm{g} / \mathrm{mg} / \mathrm{min})$

The intraparticle diffusion model has the following form [22]:

$$
q_{t}=k_{i d} \sqrt{t}+C
$$

where $k_{i d}$ is the intraparticle diffusion rate constant $\left(\mathrm{mg} / \mathrm{g} \mathrm{h}^{1 / 2}\right), C$ is the intercept $(\mathrm{mg} / \mathrm{g})$.

\subsection{Thermodynamic Parameters}

The thermodynamic parameters such as Gibbs' free energy $\left(\Delta G^{\circ}\right)$, enthalpy $\left(\Delta H^{\circ}\right)$ and entropy changes $\left(\Delta S^{\circ}\right)$ were calculated from the temperature dependent adsorption isotherms. The standard free energy change $\left(\Delta G^{\circ}\right)$ can be given by the relationship [23]:

$$
\Delta G^{\circ}=-R T \ln K_{D}
$$

where $R$ is the universal gas constant $(8.314 \mathrm{~J} /(\mathrm{mol} \mathrm{K})) . T$ is the absolute temperature in Kelvin. $K_{D}$ is the thermodynamic equilibrium constant and can be calculated as follows [24]:

$$
\begin{gathered}
K_{D}=\frac{C_{0}-C_{e}}{C_{e}} \times \frac{V}{m} \\
\ln K_{D}=\frac{\Delta S^{\circ}}{R}-\frac{\Delta H^{\circ}}{R T}
\end{gathered}
$$

$C_{0}$ is the initial concentration $(\mathrm{mg} / \mathrm{L}) . C_{e}$ is the equilibration concentration after centrifugation $(\mathrm{mg} / \mathrm{L}) . V$ is the volume $(\mathrm{mL})$ and $m$ is the mass of diatomite $(\mathrm{g})$.

\section{Results and Discussion}

\subsection{Characterisation of Diatomite}

The morphological structures of diatomaceous earth and modified diatomite were investigated by SEM. As shown in Figure 1a,b diatomite frustules are mainly divided into two main categories: centric (discoid) and pinnate (elongated). Compared with raw diatomite, thermally modified diatomite became shortened, and the particles more evenly distributed. Moreover, it can be seen that modified diatomite has reduced particle sizes and decreased the agglomeration, indicating that the calcination process increases the specific surface area of diatomite. 


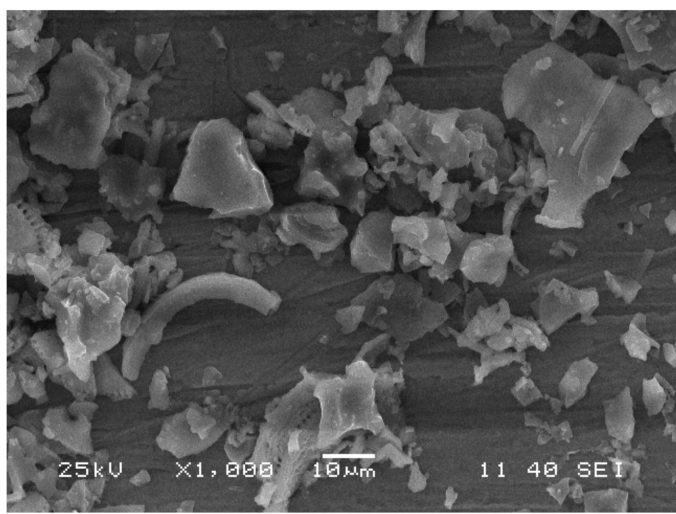

(a)

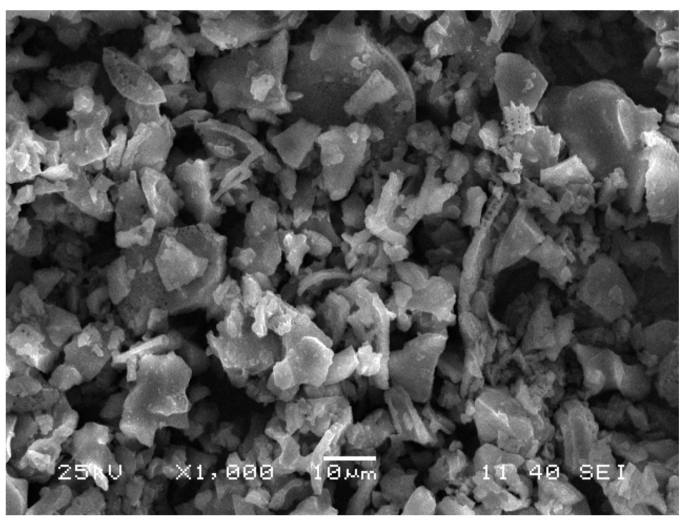

(b)

Figure 1. SEM of the (a) raw and (b) calcined $450{ }^{\circ} \mathrm{C}$ diatomite.

Figure 2 shows the FT-IR spectra of raw and modified diatomite. It labeled major adsorption peak at 3430, 1625, 1097 and $795 \mathrm{~cm}^{-1}$, corresponding to the free silanol group ( $\mathrm{SiO}-\mathrm{H}$ ) on the surface of diatomite, $\mathrm{H}-\mathrm{O}-\mathrm{H}$ bending vibration of water, siloxane (Si-O-Si) group stretching and $\mathrm{Si}-\mathrm{O}-\mathrm{H}$ vibration individually. The band between 450 and $800 \mathrm{~cm}^{-1}$ was ascribed to the superposition of the characteristic vibrations of magnesium and aluminum oxides. The change of FTIR spectra indicates O-containing groups on diatomite increase with the temperature.

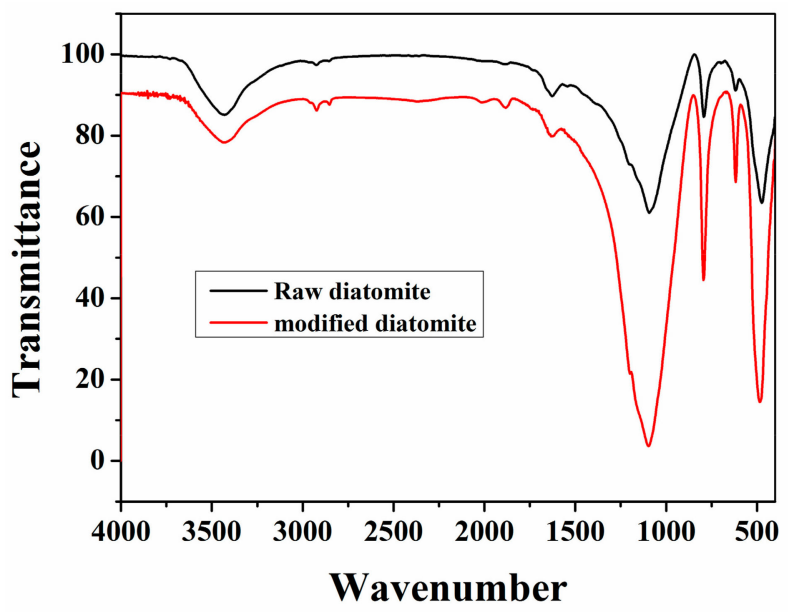

Figure 2. FT-IR spectra of diatomite samples.

Notably, the surface area and functional groups are two of the main factors influencing the adsorption performance of the adsorption materials. Chemical activation with diatomite may significantly increase the surface area of the diatomite, whereas most of the surface functional groups are also strengthened under the high temperature conditions [25]. Thus, given the adsorption capacity of the diatomite is closely related to the surface functional group, which is needed for 1-naphthol adsorptions [26].

\subsection{Analytical Determination of 1-NAP}

NAP is a colorless crystalline compound with a weak phenol odor. The maximum light absorption of 1-NAP is in UV or near UV range, which make the direct quantitative determination of 1-NAP unfavorable. However, some of 1-NAP derivatives have maximum absorption within visible light range. For example, the reaction of sulfanilic acid with 1-NAP lead to colored dyes. The mechanism between 1-NAP and sulfanilic acid has been discussed by Bourne et al. [27]. Figure 3 shows the 
maximum absorption of 1-NAP and sulfanilic acid show were at 294 and $250 \mathrm{~nm}$, respectively, while the products of them were at $518 \mathrm{~nm}$ due to redshift effects. It is likely that two types of dye 2-[(4-sulfophenyl)azo]-L-naphthoand 2,4-Bis[(4-sulfophenyl)azo]-L-naphtho also formed alike in this experiment since it agree with previous report [24]. Therefore, $518 \mathrm{~nm}$ absorption was used as characteristic peak to monitor the concentration of 1-NAP after post-treatment.

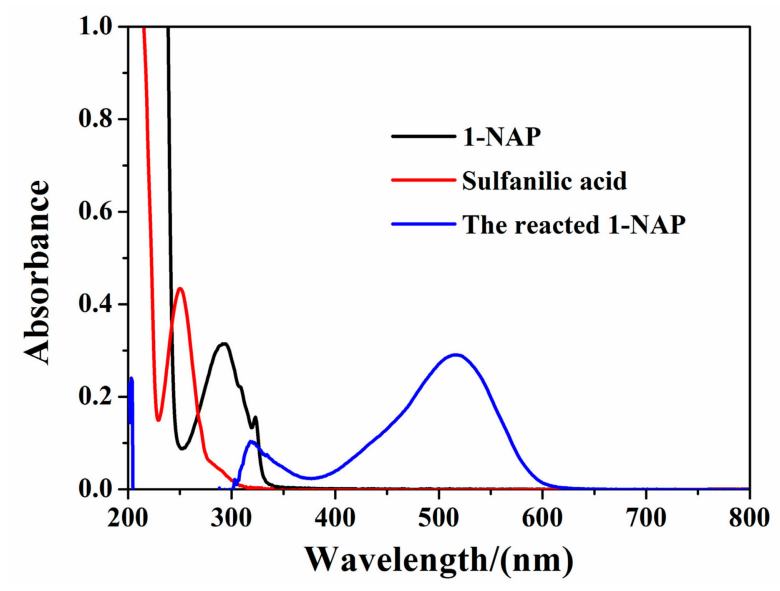

Figure 3. UV-VIS absorption scan.

The absorbance peaks intensified with the increase of 1-naphthol concentrations from 0.869 to $3.584 \mathrm{mg} / \mathrm{L}$, doubling the concentration in each step. The absorption values were recorded and plotted against the correspondence concentration to obtain calibration curve, as shown in Figure 4. These data lead to linear regression equation $y=0.22354 x-0.0124$ which showed a perfect fit $\left(R^{2}=0.9999\right)$ between the concentration of 1-naphthol and the absorbance at $518 \mathrm{~nm}$.

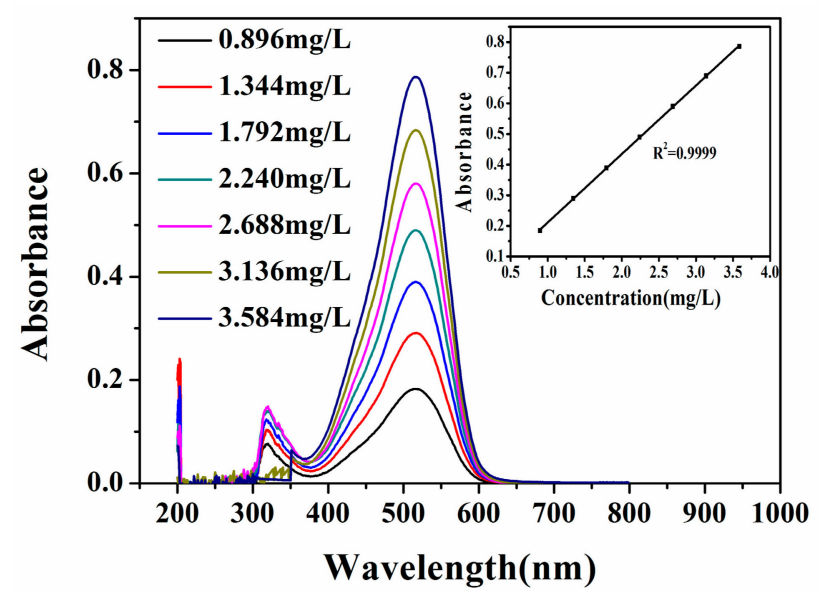

Figure 4. Calibration data for 1-NAP in solution by UV-VIS absorption after addition of sulfonic acid.

\subsection{1-NAP Absorption Experiment}

\subsubsection{Effect of Contact Time}

In order to ensure the sufficient adsorption equilibrium time, experiments were carried out over a $0-400 \mathrm{~min}$ time period. The effect of the contact time on the adsorption of 1-NAPon to the natural and thermally treated diatomite studied is illustrated in Figure 5 and shows that the initial adsorption of 1-NAP was rapid on both modified and unmodified diatomite. This can be attributed to two factors. At the initial stage, the amount of adsorption sites in excess and the 1-NAP could 
interact easily with diatomite. Secondly the concentration gradient between the bulk solution and the solid-liquid interface was higher in the initial period, so a higher adsorption rate was obtained [18]. The slowdown in adsorption rate and stagnation after a contact time of $330 \mathrm{~min}$ is due to reduced number of adsorption sites and slower diffusion. Thus, the contact time of $330 \mathrm{~min}$ was identified as the optimum contact time and used in the subsequent experiments. In addition, compared to the adsorption capability of natural diatomite towards 1-NAP, the adsorption capability of thermally treated diatomite significantly enhanced, indicating that the adsorption sites on modified diatomite could increase through thermal modification.

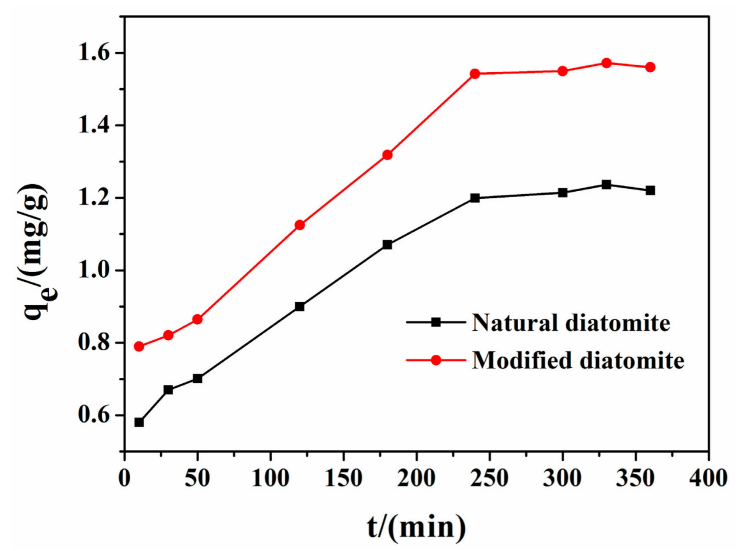

Figure 5. Diatomite adsorption 1-naphthol time versus adsorption capacity.

\subsubsection{Effect of $\mathrm{pH}$}

The $\mathrm{pH}$ is an important parameter in the adsorption process, as it directly affects the surface charge of diatomite, the species of 1-NAP and the degree of ionization in solution [11]. The effect of $\mathrm{pH}$ on the adsorption of 1-NAP on diatomite was studied between $\mathrm{pH} 1.0-13.0$, at an initial concentration of $10 \mathrm{mg} / \mathrm{L} 1-\mathrm{NAP}$, the adsorbent concentration $5 \mathrm{~g} / \mathrm{L}$, and temperature $45^{\circ} \mathrm{C}$. As shown in Figure 6, the adsorption capacity of diatomite showed a dramatic increase at $\mathrm{pH}$ value less than 3.0 and then decreased between $\mathrm{pH}$ 3.0-7.0. When $\mathrm{pH}$ values increased from 7.0 to 13.0, the adsorption capacity of natural diatomite and modified diatomite increased gradually and then with small fluctuations to a stable value. The phenomenon can be explained by the increase of $\mathrm{pH}$ and the concentration of hydroxide ion increased with hydrogen bond formation between hydroxide ion and hydroxyl group of 1-NAP. As 1-Naphthol is an acid with a pKa of 9.34 it would exist in the molecular form in an acidic solution and naphthalen-1-olate anion in an alkaline solution. At low $\mathrm{pH}$, hydroxyl groups on the surface of diatomite gained protons and the diatomite surface had a positive charge [11]. In addition, at higher $\mathrm{pH}$ values, the concentration of hydroxide ion increased. Therefore, the best $\mathrm{pH}$ of the system to remove 1-NAP from the solution using diatomite was determined to be at $\mathrm{pH}$ 3.0.

\subsubsection{Effect of Diatomite Dose}

As showed in Figure 7, the effect of diatomite dose on 1-NAP adsorption was investigated at $45^{\circ} \mathrm{C}$ and $\mathrm{pH} 3.0$ by varying the adsorbent amount from 0.1 to $0.6 \mathrm{~g} / \mathrm{L}$ with an initial 1-NAP concentration of $10 \mathrm{mg} / \mathrm{L}$. The adsorption capacity increased from 0.28 to $1.48 \mathrm{mg} / \mathrm{g}$ as the dose approached $0.5 \mathrm{~g}$, and subsequently the adsorption capacity decreased slightly. Therefore, a dose of $0.5 \mathrm{~g}$ diatomite was selected as optimum for further experiments. The increase is ascribed to more active adsorption sites on the diatomite surface with increasing the adsorbent dose [17]. The decrease could be due to aggregation of the adsorbent particles and reduction in surface area. In addition, it can be observed that the modified diatomite improved the adsorption capacity. 


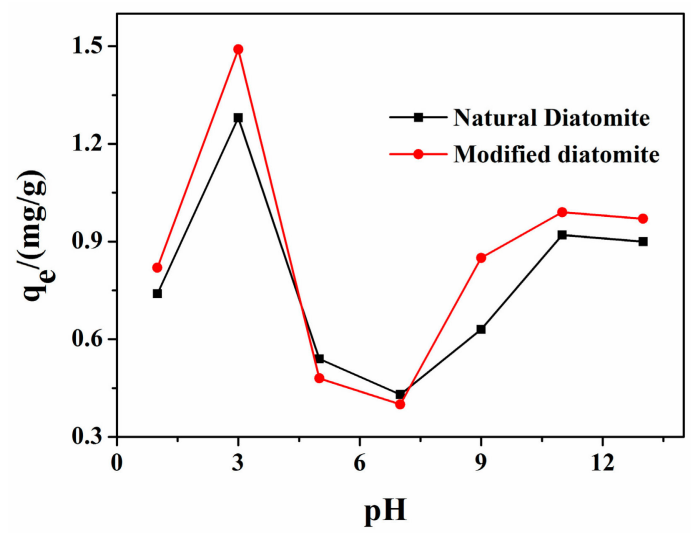

Figure 6. Effect of $\mathrm{pH}$ on the removal of 1-NAP by R-D, and C-D ((Experimental conditions: adsorbent $=5.0 \mathrm{~g} / \mathrm{L}$; initial concentration $=10 \mathrm{mg} / \mathrm{L} ; \mathrm{V}_{\text {total }}, 100 \mathrm{~mL} ; \mathrm{T}=45^{\circ} \mathrm{C}$; agitation speed $=$ $140 \mathrm{r} / \mathrm{min}$.).

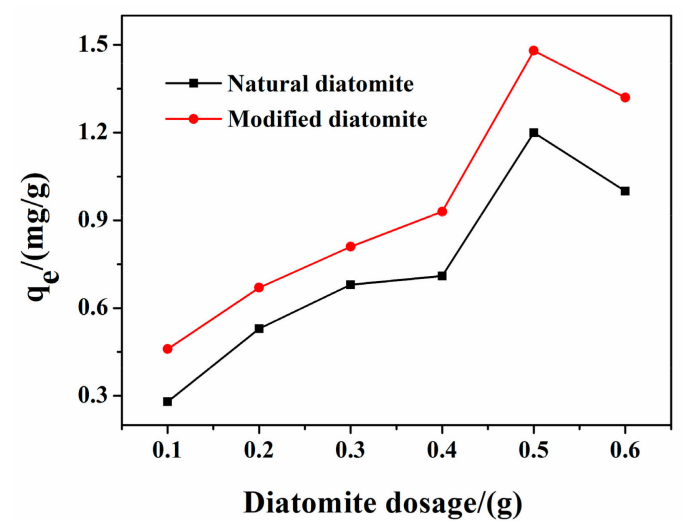

Figure 7. Effect of adsorbent dose on the removal of 1-NAP by modified diatomite.

\subsubsection{Adsorption Isotherms}

Adsorption isotherms are essential to reveal the surface properties and affinity of the adsorbent to allow the reaction pathways and mechanism of the reaction to be explored [18]. In this study, the Langmuir, Freundlich and D-R models were applied to fit the experimental data.

Figures 8-10 show best fit lines for natural and modified diatomite and 1-napthol sorption for the Langmuir $\left(1 / q_{e}\right.$ versus $\left.1 / C_{e}\right)$, Freundlich $\left(C_{e}\right.$ versus $\left.\log q_{e}\right)$ and D-R isotherms $\left(\varepsilon^{2} 10^{5}\right.$ versus $\left.\ln q_{e}\right)$.

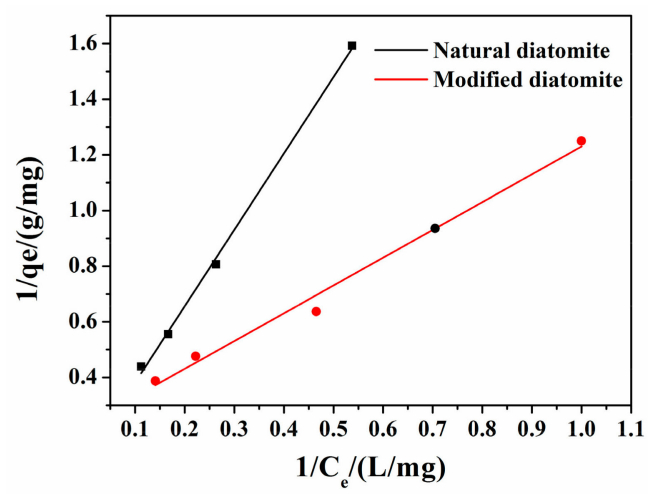

Figure 8. Diatomite adsorption 1-naphthol of Langmuir isotherm plots. Black: raw diatomite; Red: calcined $450{ }^{\circ} \mathrm{C}$ diatomite. 


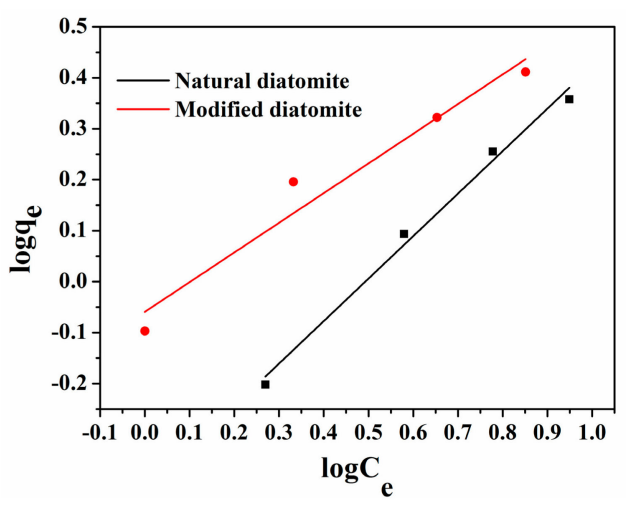

Figure 9. Diatomite adsorption 1-naphthol of Freundlich isotherm plots. Black: raw diatomite; Red: calcined $450{ }^{\circ} \mathrm{C}$ diatomite.

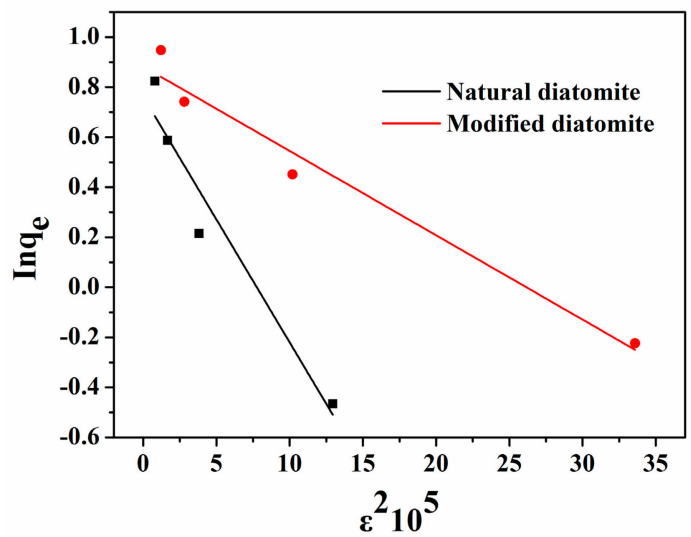

Figure 10. Diatomite adsorption 1-naphthol of D-R isotherm plots. Black: raw diatomite; Red: calcined $450{ }^{\circ} \mathrm{C}$ diatomite.

In Figures 8-10, the Langmuir, Freundlich, D-R mode descriptions of the adsorption of 1-NAP onto modified and unmodified diatomite, provide linear plots with correlation coefficients $R^{2}=0.98466$, $0.99771 ; 0.9408,0.98738 ; 0.9583,0.91902$ were obtained for natural and modified diatomite respectively. It is observed that data from both adsorbents fitted well to the Langmuir isotherm. Moreover, Figure 9 indicates the linear Freundlich isotherm plot and the standard error of parameter determination. In the event of $n<1$, it shows that marginal adsorption energy decreases with increasing surface concentration. In case of $n=1$, it indicates linear adsorption and equal adsorption energies for all sites [18]. As for $n>1$, it showed the favorable nature of adsorption and good adsorption $[19,20]$. As seen from Figure 9, while $\mathrm{n}$ value was 1.199 on raw diatomite, the value of $\mathrm{n}$ was calculated to be 1.718 on thermally modified diatomite. The result suggested that 1-NAP is favorably adsorbed by diatomite.

\subsubsection{Kinetics of Adsorption}

The pseudo-first kinetic order plots of $\ln \left(q_{e}-q_{t}\right)$ versus $t$ are shown in Figure 11. The pseudo-second order plots of $t / q_{t}$ versus $t$ are shown in Figure 12. The intra-particle diffusion model plots of $q_{t}$ versus $t^{0.5}$ are shown in Figure 13. The parameters derived from all kinetic adsorption plots for 1-NAPon original and modified diatomite are summarized in Table 1. 


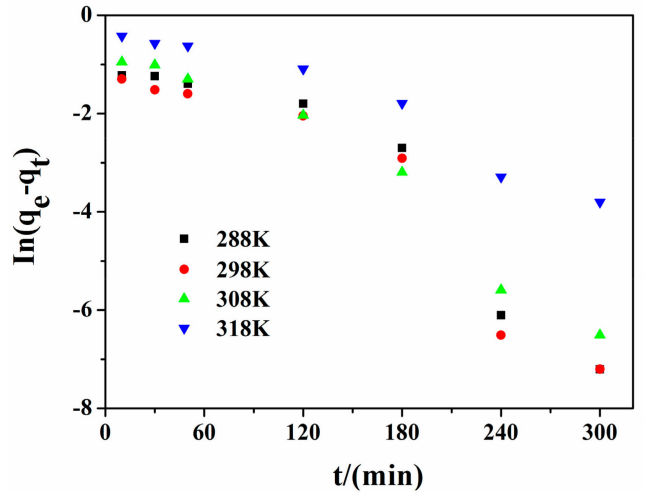

(a)

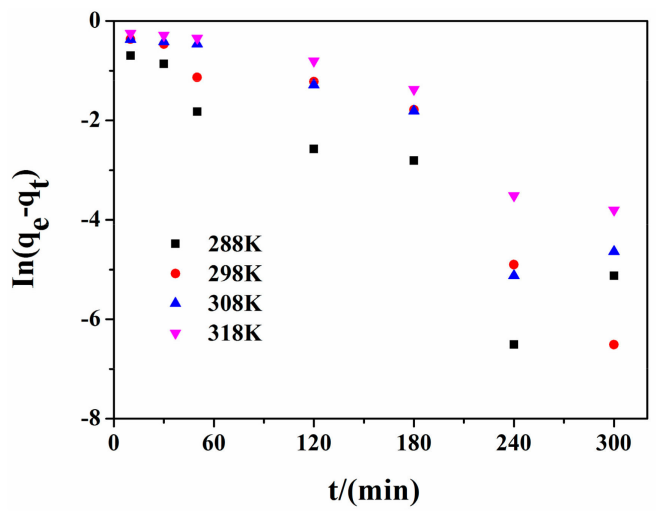

(b)

Figure 11. Effect of temperature on 1-naphthol adsorption on raw diatomite. (a) And calcined $450{ }^{\circ} \mathrm{C}$ diatomite; (b) of pseudo-first order adsorption kinetics plots.

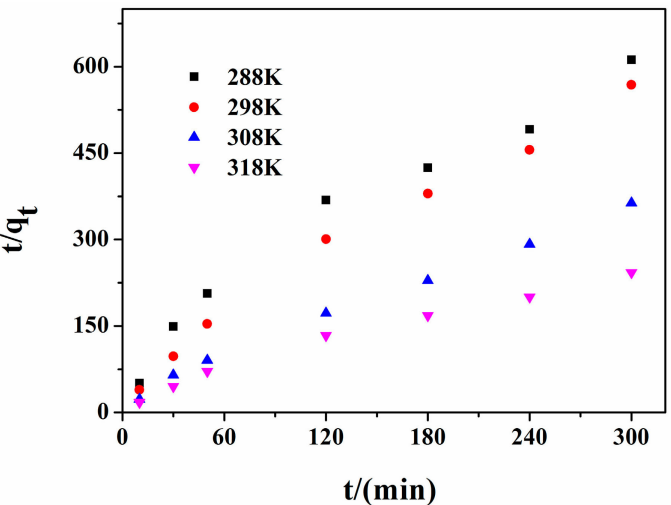

(a)

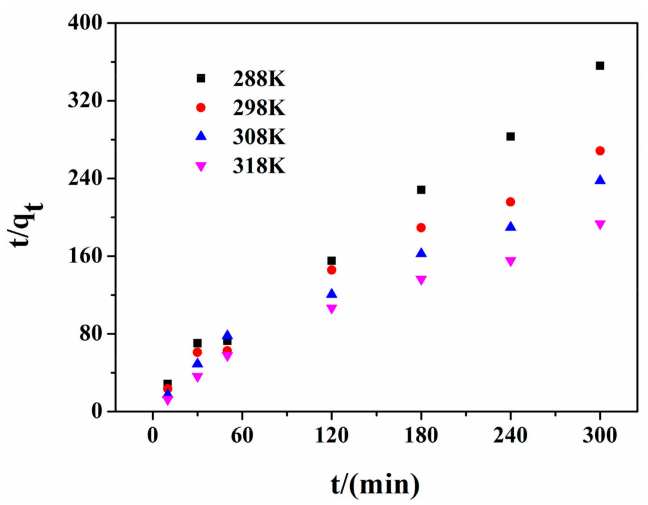

(b)

Figure 12. Effect of temperature on 1-naphthol adsorption on raw diatomite. (a) And calcined $450{ }^{\circ} \mathrm{C}$ diatomite; (b) pseudo-second order adsorption kinetics plots.

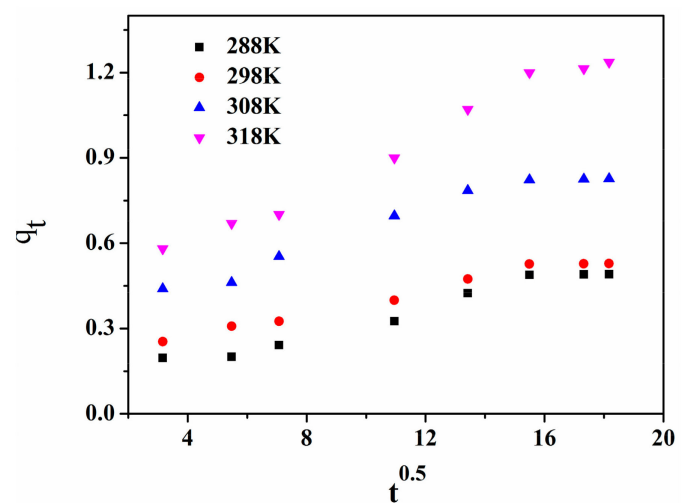

(a)

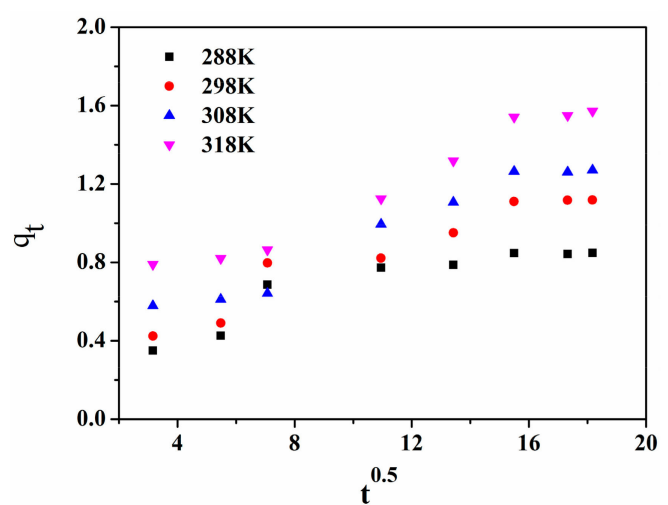

(b)

Figure 13. Effect of temperature on 1-naphthol adsorption on raw diatomite. (a) And calcined $450{ }^{\circ} \mathrm{C}$ diatomite; (b) intra-particle diffusion adsorption kinetics plots. 
Table 1. Effect of temperature on 1-naphthol sorption on raw and modified diatomite: summary of intra-particle diffusion, pseudo-first and pseudo-second order kinetics parameters.

\begin{tabular}{|c|c|c|c|c|c|c|c|c|c|c|}
\hline \multirow{2}{*}{ Adsorbent } & \multirow{2}{*}{$\mathbf{T} / \mathbf{K}$} & \multirow{2}{*}{$q_{e}, \underset{(\mathrm{mg} / \mathrm{g})}{\text { Experimental }}$} & \multicolumn{3}{|c|}{ Pseudo-First-Order Constants } & \multicolumn{3}{|c|}{ Pseudo-Second-Order Constants } & \multicolumn{2}{|c|}{$\begin{array}{c}\text { Intra-Particle } \\
\text { Diffusion Constants }\end{array}$} \\
\hline & & & $k_{1}\left(\min ^{-1}\right)$ & $q_{e}, \begin{array}{c}\text { Calculated } \\
(\mathrm{mg} / \mathrm{g})\end{array}$ & $R^{2}$ & $\begin{array}{c}k_{2} \\
(\mathrm{~g} / \mathrm{mg} / \mathrm{min})\end{array}$ & $\begin{array}{c}q_{\mathrm{e}}, \begin{array}{c}\text { Calculated } \\
(\mathrm{mg} / \mathrm{g})\end{array} \\
\text {. }\end{array}$ & $R^{2}$ & $k_{\mathrm{id}}$ & $R^{2}$ \\
\hline \multirow{4}{*}{$\begin{array}{l}\text { Natural } \\
\text { diatomite }\end{array}$} & 288 & 0.49 & $2.11 \times 10^{-2}$ & 0.75 & 0.857 & $5.90 \times 10^{-2}$ & 0.57 & 0.954 & $2.30 \times 10^{-2}$ & 0.960 \\
\hline & 298 & 0.53 & $2.10 \times 10^{-2}$ & 0.61 & 0.858 & $3.32 \times 10^{-2}$ & 0.57 & 0.984 & $2.91 \times 10^{-2}$ & 0.975 \\
\hline & 308 & 0.83 & $2.00 \times 10^{-2}$ & 0.75 & 0.944 & $4.70 \times 10^{-2}$ & 0.89 & 0.994 & $3.20 \times 10^{-2}$ & 0.947 \\
\hline & 318 & 1.24 & $1.21 \times 10^{-2}$ & 0.95 & 0.940 & $2.15 \times 10^{-2}$ & 1.34 & 0.978 & $4.72 \times 10^{-2}$ & 0.981 \\
\hline \multirow{4}{*}{$\begin{array}{l}\text { Modified } \\
\text { diatomite }\end{array}$} & 288 & 0.85 & $2.01 \times 10^{-2}$ & 0.58 & 0.807 & $4.97 \times 10^{-2}$ & 0.91 & 0.996 & $3.20 \times 10^{-2}$ & 0.807 \\
\hline & 298 & 1.12 & $1.79 \times 10^{-2}$ & 1.39 & 0.849 & $2.25 \times 10^{-2}$ & 1.22 & 0.978 & $4.73 \times 10^{-2}$ & 0.917 \\
\hline & 308 & 1.27 & $1.70 \times 10^{-2}$ & 1.28 & 0.845 & $1.77 \times 10^{-2}$ & 1.31 & 0.977 & $5.42 \times 10^{-2}$ & 0.953 \\
\hline & 318 & 1.57 & $1.32 \times 10^{-2}$ & 1.30 & 0.885 & $1.42 \times 10^{-2}$ & 1.69 & 0.971 & $6.00 \times 10^{-2}$ & 0.963 \\
\hline
\end{tabular}


Figures 11-13 showed that the pseudo-first order and the intraparticle diffusion adsorption kinetics plots are not linear over the whole time range. As shown in Table 1, the values of $q_{e}$ calculated from the pseudo-second-order model matched experimental results. The $R^{2}$ values had been determined between 0.954 and 0.996 intervals. It is observed that the adsorption of 1-NAP on raw and modified diatomite fit well with the pseudo-second-order model.

The suitability of the pseudo-second-order model for interpreting the kinetic profile of the adsorption revealed that the rate controlling step may be chemical adsorption involving valency forces through sharing or exchange of electrons between the adsorbent and the adsorbate [28].

\subsubsection{Thermodynamic Parameters}

The plots of $\ln K_{D}$ against $1 / \mathrm{T}$ are shown in Figures 14 and 15 . The $R^{2}$ values were found to be 0.99483 and 0.9913 respectively. It is evident from $R^{2}$ value that the data were well fitted. Then, the thermodynamic parameters are shown in Table 2. $\Delta H$ and $\Delta S$ can be calculated from the slope and intercept from the plot.

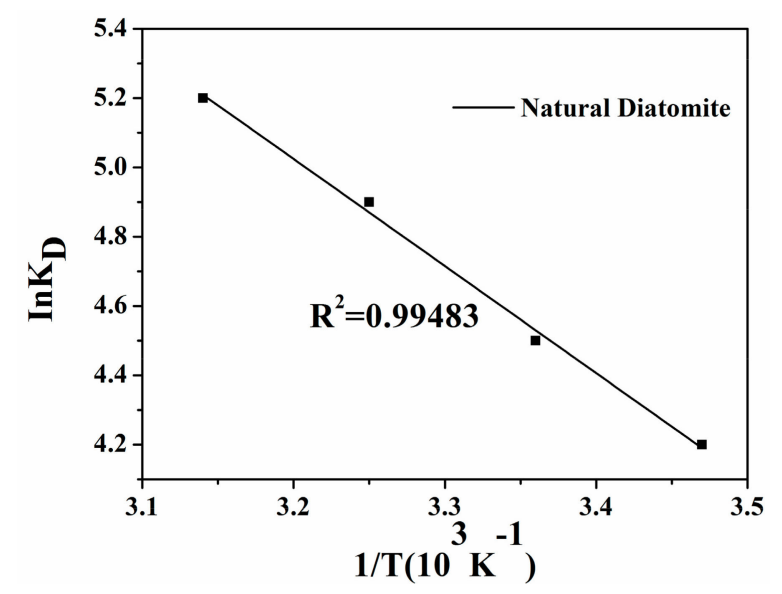

Figure 14. Raw diatomite adsorption of 1-naphthol $\ln K_{D}$ versus $1 / \mathrm{T}$ (pH 3, 1-naphthol concentration $10 \mathrm{mg} / \mathrm{L}$, diatomite consumption $0.5 \mathrm{~g}$ and adsorption time $30 \mathrm{~min}$ ).

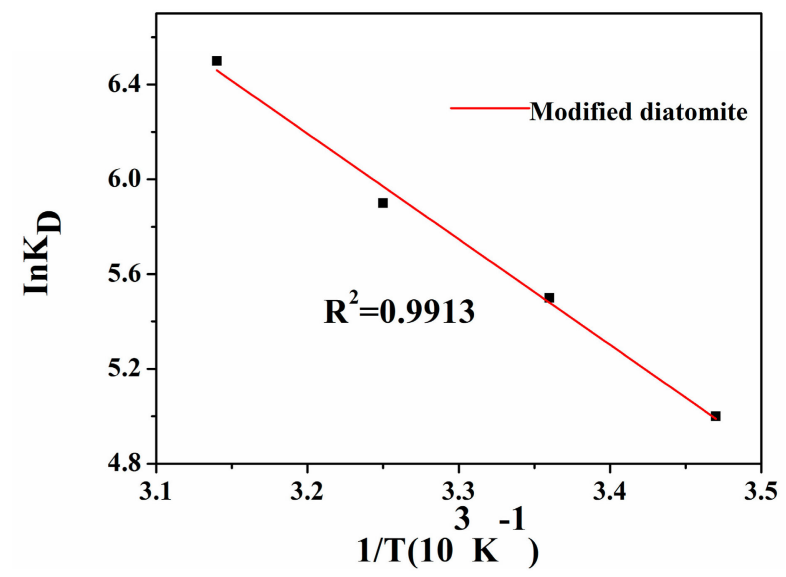

Figure 15. Calcined $450{ }^{\circ} \mathrm{C}$ diatomite adsorption of 1-naphthol $\ln K_{D}$ versus $1 / \mathrm{T}(\mathrm{pH}$ 3, 1-naphthol concentration $10 \mathrm{mg} / \mathrm{L}$, diatomite consumption $0.5 \mathrm{~g}$ and adsorption time $30 \mathrm{~min}$ ). 
Table 2. Thermodynamic parameters for raw and modified Diatomite adsorption of 1-naphthol.

\begin{tabular}{|c|c|c|c|c|c|c|}
\hline \multirow{2}{*}{ Adsorbent } & \multirow{2}{*}{$\begin{array}{c}\Delta H \\
(\mathrm{~kJ} / \mathrm{mol})\end{array}$} & \multirow{2}{*}{$\Delta S(\mathrm{~J} / \mathrm{k} / \mathrm{mol})$} & \multicolumn{4}{|c|}{$\Delta G(\mathrm{~kJ} / \mathrm{mol})$} \\
\hline & & & $288 \mathrm{~K}$ & $298 \mathrm{~K}$ & $308 \mathrm{~K}$ & $318 \mathrm{~K}$ \\
\hline $\begin{array}{c}\text { Raw } \\
\text { diatomite }\end{array}$ & 25.70 & 124 & -10.06 & -11.15 & -12.55 & -13.75 \\
\hline $\begin{array}{l}\text { Modified } \\
\text { diatomite }\end{array}$ & 37.04 & 170 & -11.97 & -13.63 & -15.11 & -17.19 \\
\hline
\end{tabular}

The values of $\Delta H$ for raw and modified diatomite were determined as 25.70 and $37.04 \mathrm{~kJ} / \mathrm{mol}$, respectively. The $\Delta H$ values were positive, indicating an endothermic process of adsorption. Typically, $\Delta H$ for physical adsorption ranges from 4 to $40 \mathrm{~kJ} / \mathrm{mol}$, compared to chemical adsorption which varies from 40 to $800 \mathrm{~kJ} / \mathrm{mol}$ [21]. In this study, the calculated $\Delta H$ value was were less than $40 \mathrm{~kJ} / \mathrm{mol}$ which showed that the adsorption process is of a physical adsorption.

The $\Delta S$ values, for modified and unmodified diatomite were 170 and $124 \mathrm{~J} / \mathrm{k} / \mathrm{mol}$, respectively. The values are positive and it is acknowledged that some structural changes have occurred between the adsorbate and adsorbents during the adsorption process. It also indicates the increasing randomness at the solid-liquid interface during the adsorption of 1-NAP on the adsorbents [22].

The $\Delta G$ values are negative, which indicated that the adsorption of 1-NAP onto raw and modified adsorbent were feasible and spontaneous. In addition, the decrease in $\Delta G$ with increasing temperature showed that better adsorption was obtained at higher temperature.

\section{Conclusions}

(1) The adsorption of 1-NAP on raw and thermal modified diatomite was endothermic and spontaneous processes, controlled by both physical and chemical mechanisms

(2) It was found that the adsorption of 1-NAP on raw and thermally modified diatomite could best be explained by the pseudo second-order model.

(3) For raw and thermal modified diatomite, the experimental data have been applied on Langmuir, Freundlich and D-R isotherm models. The Langmuir adsorption isotherm model fitted better in the temperature gradients studied.

(4) The sorption of 1-NAP is strongly affected by $\mathrm{pH}$, temperature and diatomite dose. Compared with natural diatomite, it can be observed that the modified diatomite significantly improve the adsorption capacity (about 2 times at $298 \mathrm{~K}$ ).

Acknowledgments: This work was supported by National Natural Science Foundation of China (No. 51308078 and No. 51604113), Natural Science Foundation of Hunan Province, China (No. 2016JJ6040).

Author Contributions: Liping Wang designed the conception; Lili Cao performed the experiments; Kelin Li contributed analysis tools; Yuezhou Zhang provided important advice on the concept of methodology and structuring of the manuscript; Xiuzhen Yang written the manuscript; Andrew Hursthouse reviewed the study and edited the manuscript prior to submission.

Conflicts of Interest: The authors declare no conflict of interest.

\section{References}

1. Zhao, G.X.; Li, J.X.; Wang, X.K. Kinetic and thermodynamic study of 1-naphthol adsorption from aqueous solution to sulfonated graphene nanosheets. Chem. Eng. J. 2011, 173, 185-190. [CrossRef]

2. Zhang, W.M.; Hong, C.H.; Pan, B.C.; Zhang, Q.J.; Jiang, P.J.; Jia, K. Sorption enhancement of 1-naphthol onto a hydrophilic hyper-cross-linked polymer resin. J. Hazard. Mater. 2009, 163, 53-57. [CrossRef] [PubMed]

3. Burgos, W.D.; Pisutpaisal, N.; Tuntoolavest, M.; Chorover, J.; Unz, R.F. Biodegradation of 1-naphthol in the presence of humic acid. Environ. Eng. Sci. 2000, 17, 343-351. [CrossRef]

4. Zhu, H.C.; Shen, Z.M.; Tang, Q.L.; Ji, W.C.; Jia, L.J. Degradation mechanism study of organic pollutants in ozonation process by QSAR analysis. Chem. Eng. J. 2014, 255, 431-436. [CrossRef] 
5. Gcina, M.; Xavier, Y.K.; Mbianda, A.K. Photocatalytic degradation of the diazo dye naphthol blue black in water using $\mathrm{MWCNT} / \mathrm{Gd}, \mathrm{N}, \mathrm{S}-\mathrm{TiO}_{2}$ nanocomposites under simulated solar light. J. Environ. Sci. 2015, 33, 219-228.

6. Sheng, G.D.; Shao, D.D.; Ren, X.M.; Wang, X.Q.; Li, J.X.; Chen, Y.X.; Wang, X.K. Kineticsand thermodynamics of adsorption ofionizable aromatic compounds fromaqueous solutions by as-prepared and oxidized multiwalled carbon nanotubes. J. Hazard. Mater. 2010, 178, 505-516. [CrossRef] [PubMed]

7. Ou, H.X.; Chen, Q.H.; Pan, J.M.; Zhang, Y.L.; Huang, Y.; Qi, X.Y. Selective removal of erythromycin by magnetic imprinted polymers synthesized from chitosan-stabilized Pickering emulsion. J. Hazard. Mater. 2015, 289, 28-37. [CrossRef] [PubMed]

8. Wang, L. Application of activated carbon derived from 'waste' bamboo culms for the adsorption of azo disperse dye: Kinetic, equilibrium and thermodynamic studies. J. Environ. Manag. 2012, 102, 79-87. [CrossRef] [PubMed]

9. Ge, X.Y.; Tian, F.; Wu, Z.L.; Yan, Y.J.; Cravotto, G.; Wu, Z.S. Adsorption of naphthalene from aqueous solution on coal-based activated carbon modified by microwave induction: Microwave power effects. Chem. Eng. Process. 2015, 91, 67-77. [CrossRef]

10. Xia, P.; Wang, X.J.; Wang, X.; Song, J.K.; Wang, H.; Zhang, J.; Zhao, J.F. Struvite crystallization combined adsorption of phosphate and ammonium from aqueous solutions by mesoporous $\mathrm{MgO}$ loaded diatomite. Coll. Surf. A Physicochem. Eng. Asp. 2016, 506, 220-227. [CrossRef]

11. Li, W.G.; Gong, X.J.; Li, X.; Zhang, D.Y.; Gong, H.N. Removal of Cr (VI) from low-temperature micro-polluted surface water by tannic acid immobilized powdered activated carbon. Bioresour. Technol. 2012, 113, $106-113$. [CrossRef] [PubMed]

12. Yu, Y.C.; Hu, Z.J.; Wang, Y.; Gao, H.W. Magnetic SN-functionalized diatomite for effective removals of phenols. Int. J. Miner. Process. 2017, 162, 1-5. [CrossRef]

13. Li, J.; Guan, P.; Zhang, Y.; Xiang, B.; Tang, X.H.; She, H.D. A diatomite coated mesh with switchable wettability for on-demand oil/water separation and methylene blue adsorption. Sep. Purif. Technol. 2017, 174, 275-281. [CrossRef]

14. Aivalioti, M.; Vamvasakis, I.; Gidarakos, E. BTEX and MTBE adsorption onto raw and thermally modified diatomite. J. Hazard. Mater. 2010, 178, 136-143. [CrossRef] [PubMed]

15. Ghaedi, M.; Sadeghian, B.; Pebdani, A.A.; Sahraei, R.; Daneshfar, A.; Duran, C. Kinetics, thermodynamics and equilibrium evaluation of direct yellow 12 removal by adsorption onto silver nanoparticles loaded activated carbon. Chem. Eng. J. 2012, 187, 133-141. [CrossRef]

16. Kaçan, E.; Kütahyalı, C. Adsorption of strontium from aqueous solution using activated carbon produced from textile sewage sludges. J. Anal. Appl. Pyrol. 2012, 97, 149-157. [CrossRef]

17. Caliskan, N.; Kul, A.R.; Alkan, S.; Sogut, E.G.; Alacabey, I. Adsorption of Zinc (II) on diatomite and manganese-oxide-modified diatomite: A kinetic and equilibrium study. J. Hazard. Mater. 2011, 193, 27-36. [CrossRef] [PubMed]

18. Dural, M.U.; Cavas, L.; Papageorgiou, S.K.; Katsaros, F.K. Methylene blue adsorption on activated carbon prepared from Posidoniaoceanica (L.) dead leaves: Kinetics and equilibrium studies. Chem. Eng. J. 2011, 168, 77-85. [CrossRef]

19. Singh, V.K.; Tiwari, P.N. Removal and recovery of chromium (VI) from industrial waste water. J. Chem. Technol. Biot. 1997, 69, 376-382. [CrossRef]

20. Yang, X.Z.; Shi, Z.; Liu, L.S. Adsorption of Sb from aqueous solution by GFGO in batch and fixed-bed systems. Chem. Eng. J. 2015, 260, 444-453. [CrossRef]

21. Foo, K.Y.; Hameed, B.H. Adsorption characteristics of industrial solid waste derived activated carbon prepared by microwave heating for methylene blue. Fuel Process. Technol. 2012, 99, 103-109. [CrossRef]

22. Wu, F.C.; Ruling, T.; Rueyshin, J. Initial behavior of intraparticle diffusion model used in the description of adsorption kinetics. Chem. Eng. J. 2009, 153, 1-8. [CrossRef]

23. Wang, S.; Li, H. Dye adsorption on unburned carbon: Kinetics and equilibrium. J. Hazard. Mater. 2005, 126, 71-77. [CrossRef] [PubMed]

24. Awwad, A.M.; Farhan, A.M. Equilibrium, Kinetic and Thermodynamics of Biosorption of Lead (II) Copper (II) and Cadmium (II) Ions from Aqueous Solutions onto Olive Leaves Powder. Am. J. Chem. 2012, 2, $238-244$. [CrossRef] 
25. Titirici, M.M.; White, R.J.; Brun, N.; Budarin, V.L.; Su, D.S.; del Monte, F.; Clark, J.H.; MacLachlan, M.J. Sustainable carbon materials. Chem. Soc. Rev. 2015, 44, 250-290. [CrossRef] [PubMed]

26. Qi, Z.C.; Hou, L.; Zhu, D.Q.; Ji, R.; Chen, W. Enhance Transport of Phenanthrene and 1-Naphthol by Colloidal Graphene Oxide Nanoparticles in Saturated Soil. Environ. Sci. Technol. 2014, 48, 10136-10144. [CrossRef] [PubMed]

27. Bourne, J.R.; Kut, O.M.; Lenzner, J.; Maire, H. Kinetics of the diazo coupling between 1-naphthol and diazotized sulfanilic acid. Ind. Eng. Chem. Res. 1990, 29, 1761-1765. [CrossRef]

28. Deng, L.; Shi, Z.; Li, B.; Yang, L.; Luo, L.; Yang, X. Adsorption of Cr(VI) and Phosphate on Mg-Al Hydrotalcite Supported Kaolin Clay Prepared by Ultrasound-Assisted Coprecipitation Method Using Batch and Fixed-Bed Systems. Ind. Eng. Chem. Res. 2014, 53, 7746-7757. [CrossRef]

(C) 2017 by the authors. Licensee MDPI, Basel, Switzerland. This article is an open access article distributed under the terms and conditions of the Creative Commons Attribution (CC BY) license (http:/ / creativecommons.org/licenses/by/4.0/). 